\title{
Effects of chronic administration and withdrawal of d-amphetamine upon daily activity levels of squirrel monkeys
}

\author{
VINCENT P. HOUSER \\ Psychotropic Drug Laboratory \\ Veterans Administration Hospital \\ Perry Point, Maryland 21902
}

\begin{abstract}
Two squirrel monkeys were placed in activity cages for a 7-week experimental period. Activity levels were recorded every hour $24 \mathrm{~h}$ a day. Animals received daily injections of d-amphetamine sulfate (.5, $1.0 \mathrm{mg} / \mathrm{kg}$ ) for 7 consecutive days followed by 14 days of saline administration (i.e., drug withdrawal). Both dosages of amphetamine were able to reliably elevate mean activity levels during the $12 \mathrm{~h}$ after drug administration. During the drug withdrawal periods animals demonstrated significant decrements in baseline activity levels. These effects were interpreted to suggest that chronic amphetamine administration may produce long-lasting biochemical changes in the central nervous system of the squirrel monkey which are reflected by the decreased motor activity noted after the drug is withdrawn.
\end{abstract}

Amphetamine has been reported to produce a variety of effects upon behavior which include an increase in spontaneous motor activity (Irwin, Slabok, \& Thomas, 1958). Although this effect of amphetamine has been substantiated by numerous studies, little attention has been focused on the behavior of various animal species when chronic administration of the drug ceases. In one of the few reports concerning the effects of amphetamine withdrawal, Houser and Van Hart (1974) have noted that during withdrawal from 7 days of chronic drug administration (i.e., $1.0,2.0 \mathrm{mg} / \mathrm{kg}$ ) rats demonstrated significant elevations in baseline activity as measured in activity wheels. These data are in agreement with an earlier paper by Houser (1973a) who reported that rats demonstrated increased barpress rates during the unreinforced portions of a fixed-interval schedule, while the animals were undergoing a 5-day amphetamine withdrawal period. Similar increases in the activity of rats during amphetamine withdrawal have also been noted by Ross and Schnitzer (1963).

In contrast, Houser (1973b) has reported that squirrel monkeys demonstrated reduced barpress rates under a modified Sidman avoidance schedule during withdrawal from 7 days of amphetamine $(1.0,2.0 \mathrm{mg} / \mathrm{kg} / \mathrm{day})$ administration. These results suggest that the squirrel monkey may demonstrate changes in activity levels during drug withdrawal that are in contrast to the changes demonstrated by rodents. The present report was an attempt to monitor activity levels in squirrel monkeys $24 \mathrm{~h}$ a day to determine the effects of chronic administration and withdrawal of d-amphetamine sulfate upon this measure.

The author wishes to express his gratitude to Mr. Luther $R$. Gilliam, Chief of the Medical Illustration Service, VA Hospital, Perry Point, Maryland, and Mrs. Dale A. Van Hart for their help in preparing the figure used in this report.

\section{METHOD}

The subjects for this study consisted of two male squirrel monkeys (DICK, ROSCOE) weighing $237 \mathrm{~g}$ and $397 \mathrm{~g}$, respectively. Both animals were kept on an ad-lib food and water schedule throughout the study. The apparatus used to monitor spontaneous motor activity has been described in detail elsewhere (Love \& Houser, 1974). Briefly, the apparatus consisted of a wire mesh cage (26 in. wide, $17.25 \mathrm{in}$. high, and 23.5 in. deep) that was suspended inside a wooden enclosure in a way that allowed the cage to swing in any lateral direction. Any movement of the animal caused the cage to swing slightly. This movement was detected by a concentric brass cylinder assembly. The outer cylinder was connected to the fixed wooden enclosure, while the inner cylinder was connected to the cage. Thus, movement of the cage brought the inner cylinder in contact with the outer cylinder, thus conducting an electrical impulse that was fed through an electromechanical pulse former and then into a printout counter. This counter cumulated the number of activity counts and printed this sum every hour $24 \mathrm{~h}$ a day. Initially the two monkeys were placed in the cage for 14 weeks to adapt them to this environment and to establish stable activity levels. The experiment proper lasted 7 weeks. During the first week animals were injected with $.9 \%$ saline followed by a week of amphetamine $(1.0 \mathrm{mg} / \mathrm{kg} / \mathrm{day})$ administration. The next 2 weeks consisted of saline administration followed by a week of drug $(.5 \mathrm{mg} / \mathrm{kg} /$ day $)$ administration. During the final 2 weeks, both animals were given saline. D-amphetamine sulfate was dissolved in $.9 \%$ saline and administered intramuscularly in one daily injection in a volume of $.5 \mathrm{ml} / \mathrm{kg}$. All injections were given at 8:00 a.m. Fresh food (i.e., Purina Monkey Chow) was delivered each day at 8:30 a.m. and animals had free access to water throughout the experimental and baseline periods. The experimental room was kept at a constant $80^{\circ} \mathrm{F}$ with a relative humidity of $50 \%-60 \%$. The lights in the experimental room were illuminated between 6:00 a.m. and 6:00 p.m. each day.

\section{RESULTS}

Figure 1 presents the mean number of activity counts per hour for both animals during the entire 7-week experimental period. The top portion of this figure 


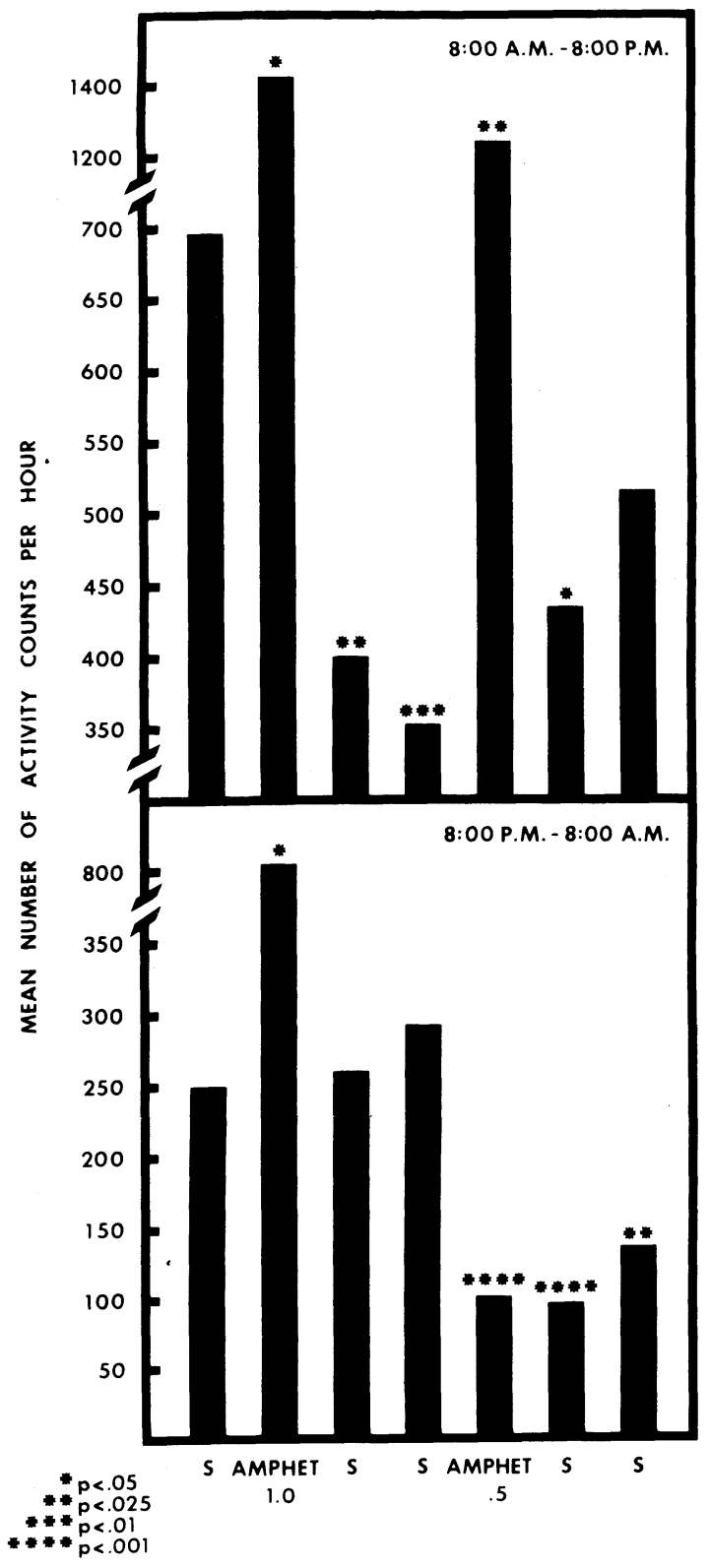

Figure 1. Mean number of activity counts per hour for both animals during the 7-week experimental period. Probability levels refer to $t$ tests for related samples performed between the first saline week and the remaining six weeks of the experiment. All dosages of amphetamine are given in $\mathrm{mg} / \mathrm{kg}$. Saline administration (S) occurred during 5 weeks of the experimental period.

presents the mean activity counts during the twelve hours immediately after drug or saline administration (i.e., 8:00 a.m.-8:00 p.m.), while the bottom portion of the figure presents the data collected during the evening hours (i.e., 8:00 p.m.-8:00 a.m.). The data in this figure indicate that amphetamine was able to significantly $(\mathrm{p}<.05)$ raise the mean activity level during the $12-\mathrm{h}$ period that followed administration of either dose of the drug. Statistical comparisons were made between the first saline week (i.e., baseline period) and the following 6 weeks using a t test for related samples. Furthermore, withdrawal of the drug during Weeks 3,4 , and 6 led to significant decrements in activity. Both the initial drug effect and the withdrawal effects appeared to be dose related in that the higher dose (i.e., $1.0 \mathrm{mg} / \mathrm{kg}$ ) produced higher elevations in activity and greater decrements during withdrawal than the lower dosage.

The activity data during the evening hours demonstrated less of a drug effect than the data that were collected during the day. Only the highest dose (i.e., $1.0 \mathrm{mg} / \mathrm{kg}$ ) significantly elevated the evening activity level. The $.5 \mathrm{mg} / \mathrm{kg}$ dosage reliably reduced the mean number of activity counts, and this reduced level was maintained throughout the final 2 weeks of the experiment. The fact that the low dose evening data showed no direct effect probably indicates that the stimulating effects of this dosage had dissipated within $12 \mathrm{~h}$.

\section{DISCUSSION}

The present data indicate that squirrel monkeys demonstrate significant decrements in mean daily activity during withdrawal from chronic amphetamine administration. This reduction in activity is seen primarily during the daylight portion of the activity cycle, however. Nighttime activity was reduced during amphetamine withdrawal only under the lower dose. These results, in turn, are in contrast to rodent data (Houser \& Van Hart, 1974) which indicate that rats demonstrate increased activity during withdrawal from chronic amphetamine administration. It would thus appear that amphetamine withdrawal produces distinct effects in these two species, elevating activity in rats while producing decrements in activity in squirrel monkeys.

Finally, the fact that baseline activity is significantly altered long after drug administration ceases suggests that amphetamine may produce long-lasting biochemical changes in the central nervous system of the squirrel monkey. A discussion of this possibility has been presented earlier (Houser, 1973b) which suggested that adrenergic activity may be depressed during drug withdrawal, thus leading to a reduction in motor activity. The present results are compatible with this hypothesis.

\section{REFERENCES}

Houser, V. P. Influence of changes in adrenergic and cholinergic activity upon acquisition of operant discrimination in albino rats. Psychological Reports, 1973a, 32, 1311-1327.

Houser, V. P. Modulation of avoidance behavior in squirrel monkeys after chronic administration and withdrawal of d-amphetamine or $\alpha$-methyl-p-ty rosine. Psychopharmacologia (Berl.), 1973b, 18, 213-234.

Houser, V. P., \& Van Hart, D. A. Effects of withdrawal from chronic amphetamine administration on activity levels of albino rats. Psy chological Reports, 1974, 35, 307-310.

Irwin, F., Slabok, J., \& Thomas, A. Individual differences: I. Correlation between control locomotor activity and sensitivity to stimulant and depressant drugs. Journal of Pharmacology to stimulant and depressant drugs. Journal of

Love; W. S., \& Houser, V. P. A reliable method for continuously monitoring motor activity in unrestrained squirrel monkeys. Behavior Research Methods \& Instrumentation, 1974, 6, 325-326.

Ross, S. \& Schnitzer, S. B. Further support for a placebo effect in the rat. Psy chological Reports, 1963, 13, 461-462.

(Received for publication December 23, 1974.) 